\title{
What is the JRCPE for?
}

\author{
${ }^{1} \mathrm{R}$ Martyn Bracewell, ${ }^{2}$ Miles D Witham, ${ }^{3}$ Andrew R Medford, ${ }^{4}$ Allan W Beveridge, ${ }^{5}$ Yeong Yeh Lee, \\ ${ }^{6}$ Seamus G O'Mahony \\ ${ }^{1}$ Editor-in-Chief, Bangor University, Bangor and Walton Centre NHS Foundation Trust, Liverpool, UK; ${ }^{2}$ Clinical Editor, Ninewells Hospital, \\ Dundee,UK; ${ }^{3}$ Education Editor, North Bristol Lung Centre, Bristol, UK; ${ }^{4}$ History Editor, Queen Margaret Hospital, Dunfermline, UK; \\ ${ }^{5}$ Associate Clinical Editor, Hospital Universiti Sains Malaysia, Malaysia; ${ }^{6}$ Associate History Editor, Cork University Hospital, Cork, Ireland
}

This summer brings a mostly new editorial team to the JRCPE (Andrew Medford continues to manage the Education section), and, with a significant changing of the guard, now is perhaps a good time to stop and reflect on what the JRCPE is for. Who is our readership? What is the JRCPE's mission? What niche should the JRCPE occupy in the publishing landscape? How should the JRCPE evolve in the future?

The first question is perhaps the easiest to answer. The main readership of the JRCPE is of course the membership of the RCPE. Traditionally we have published articles broadly of UK interest. However, with an expanding international membership, we hope to capture the interest of this segment of our readership too. The JRCPE also encompasses a readership beyond the College, across the UK and internationally, with free online article access and PubMed listing bringing the JRCPE to a global audience. It is important that the content reflects the interests of this global audience as well as that of practitioners in the UK. To this end, we have recruited an associate editor (international), Yeong Yeh Lee, who will assist the editorial team in soliciting and editing international clinical papers. Reassuringly, the last membership survey suggested that the JRCPE's content was popular with Members, although we must be wary of assuming that those responding are representative of all potential readers.

The mission of the JRCPE then needs to align with the mission of the College - namely to raise standards of physicianly practice, to improve the quality of patient care, to educate and to influence healthcare policy. What sort of content would best deliver this aim? Research reports are one part of this, particularly research with a direct impact on patient care. The JRCPE also has an important role in supporting quality improvement; audit alone is insufficient to drive improvement and we welcome papers describing innovative methods to improve services, with robust evaluation, informed by the rapidly growing field of improvement science. We are also keen to expand the number of systematic reviews that are published in the JRCPE.

Case reports continue to be an important feature of the JRCPE; we are most interested in cases which deliver clear learning points applicable to a wide area of clinical practice. 'Fascinomas' have their place in the literature, but our practice cannot be driven by rarities.

Education remains of paramount importance to the $J R C P E$ and its readership but is a continually evolving area reflecting research developments and innovation. The editorial team continues to commission high quality review articles from keynote speakers at symposia. This also allows the speakers the opportunity to collaborate with their teams in generating manuscripts that will summarise the evidence base, where there are gaps in the evidence and highlight ongoing areas for research or future developments. Rapporteur reports from the symposia are commissioned; these allow relatively junior authors the chance to develop their writing skills. Another important aspect of the JRCPE Education section is to generate debate and the editorial team continues to commission manuscripts from key opinion leaders and experts with contrasting perspectives on the same topic. Finally, CME papers and MCQs continue to be commissioned from the College CME Programme and provide a further source of education.

We are also looking to build on the success of the History section. We would like to widen the range of subjects we cover and should remind readers that we not only publish papers on the history of Scottish medicine but are also keen to increase the number of papers that are concerned with the medical history of countries from all around the world. We are aiming to encourage submissions from non-medical authors, especially historians of medicine. An exciting development is the decision to increase the scope of the section to include the Medical Humanities. This is a growing field and we would welcome papers on all aspects of the subject, such as the relationship between medicine and art, literature and philosophy. Potential papers could include accounts of doctors who have contributed to the arts, the representation of medicine and disease in literature and the visual arts, and the ethical and cultural issues that the medical humanities raise about the role of medicine in society, both past and present.

Most of the above content can be found in other journals, or increasingly through online content. So what 
niche does the JRCPE fill? One unique feature of the $J R C P E$ is that it provides all of the above in a single, easily accessible place. The JRCPE also acts as a window on the College, supporting and enhancing the other activities that the College undertakes. Furthermore, the JRCPE provides professional development support and contemporary thinking from our peers, and should act as a driver for innovation and change. Calibrating one's practice against, and learning from, our peers is a critical part of what makes medicine a profession, and the JRCPE provides a crucial role in this.

So finally, quo vadis? The death of paper-based journals has been predicted for several years now, and while such predictions still appear premature, the world is slowly but surely moving to online content and resources. It is likely that social media will become more important and it seems clear that the JRCPE will need to at least follow, and better still lead, this global trend. If the JRCPE is to remain relevant, we will need to not only react to external changes and reflect current thinking and practice, but to lead from the front - helping the College to set the political agenda, and drive innovation in how we deliver care to our patients, how we educate each other, and how we maintain and improve standards of practice around the world.

For the JRCPE to thrive, an active partnership is needed between the editorial team and you, the readership. It is your journal, and only by contributing will your journal deliver the content that you want to see. At the same time, the JRCPE will strive to enhance your publishing experience with us through an improvement in the submission, review and publication process; changes which will help us attract high-quality work as we move towards gaining an impact factor.

We therefore finish with a request, especially to our membership - please send us your material. If you have research, quality improvement work, a case or an idea that is of national or international relevance, we want to hear about it - as will your peers and colleagues.

\section{THE COLLEGE JOURNAL PRIZE}

The College Journal Prize 20I4, sponsored by the Senior Fellows' Club, has been won by B Quinn et al for their paper 'A masquerading mass: an unusual presentation of IgG4related systemic disease with tubulointerstitial nephritis'. This paper can be read in issue 2 , 2014 at http://www.rcpe.ac.uk/sites/default/files/harty.pdf

A prize of $£ 250$ will be awarded to the first-named (or corresponding) author of an original research paper on a clinical topic, deemed by a panel of judges to be the best paper by a doctor-in-training (i.e. pre-consultant level) published in The Journal of the Royal College of Physicians of Edinburgh in issues 3 and 4,20I4 and issues I and 2, 20I5. The paper will be selected by a panel of judges, including a senior Fellow, an active clinician and a member of the Editorial team. The prize-winner will be invited to give a short oral presentation based on his/her paper at the Trainees and Members' symposium in October 2015.

Further details may be obtained from the Editorial Office, RCPE, 9 Queen Street, Edinburgh EH2 IJQ, tel +44 (0) I 3 I 2473652 or email editorial@rcpe.ac.uk. 